\title{
Terviklik teooria psüühika ja selle arengu kohta
}

\author{
Jaan Kõrgesaar ${ }^{\mathrm{a}}$ \\ ${ }^{a}$ Tartu Ülikool
}

Toomela, A. (2016). Kultuur, kõne ja Minu Ise. Tallinn: Eesti Keele Sihtasutus. Toomela, A. (2017). Minu Ise areng: inimlapsest Inimeseks. Tartu: Väike Vanker.

Tallinna ülikooli kultuuri- ja neuropsühholoogia professor Aaro Toomela on loonud psüühika (Minu Ise) tervikkäsitluse. Selles argumenteeritakse inimese (teadvuse) erilisuse, selle kultuurilise tingituse ja kõnelise vahendatuse poolt. Erilisus puudutab teisi teadaolevaid maiseid eluvorme, jättes autori sõnul kõrvale tundmatu: tehisintellekti, mõistusliku elu universumis ja Looja. Teooriaosa esitatakse uurimistulemuste analüüsiga võrreldes kompaktsemalt, kuid liigendatult ajaloolis-filosoofiliste ekskurssidega. Toomela teostest aimub Võgotski (1934/2004) - sarnased on nii akadeemilis-poleemiline stiil kui ka õpetlaslikentsüklopeediline haare. Akadeemiline sügavus mõjub erilisena. Autori sõnul seletavad eestikeelsete süvakäsitluste nappust tänapäeva „teadusbürokraatide märgade unenägude sisuks olevad jaburad kriteeriumid“ (II kd, lk 475).

Püüan määratlusi lükkides anda teooriast ülevaate, alustades esimesest köitest, kuhu on kätketud Toomela teooria tuumik (mõnele harvale kirjakohale teisest köitest viitan allpool eraldi märkega II $k d$ ). Psüühika ehk Minu Ise „on elusa mateeria eriliselt organiseeritud vorm, kelle sihipärane enesele kui tervikule kahjulikke keskkonnamõjusid ennetav käitumine põhineb individuaalsel kogemusel“ (lk 57). Sellise määratluseni aitasid autoril jõuda 20. sajandi alguse Briti poliitik ja sotsioloog Hobhouse ning teise maailmasõja paiku Pavlovi teooriat arendanud Anohhin.

Käitumiskeskkond ehk omailm eristub (geograafilisest) väliskeskkonnast; omailm jaotub aistitavaks ja tegevusmaailmaks (lk 79). Eelneva sedastuseni jõudis autor, vastandudes Descartes'ile ning toetudes muu hulgas Koffkale, Eddingtonile ja Uexküllile. Keskkond on asja ümbritsev väline maailm (lk 101). Seisundilised-staatilised keskkonnaliigid on mõjuv ja mõjuta keskkond, kusjuures omailm on mõjuva alaliik (lk 102-103). Omailmas eristatakse Koffka järgi käitumiskeskkonda (lk 104), mille alaliigid on kattuv ehk sotsiaalne ja 
individuaalne keskkond (lk 106-107). Kultuurikeskkond on sotsiaalse alaliik (lk 197). Keskkondi saab tekkedünaamika järgi liigitada mõjuvaks juhuslikpassiivseks, liigiomaseks (omailm) ja individuaalseks (käitumis-)tehiskeskkonnaks, sotsiaalseks keskkonnaks, sotsiaalseks teise organismi meeltele orienteeritud tehiskeskkonnaks ja kultuurikeskkonnaks ehk hierarhiliselt kumuleeruvaks sotsiaalseks keskkonnaks (lk 107-113). Indiviidi keskkonnad jagunevad arengu-, toetavaks ning siin-ja-praegu hetkekeskkonnaks (lk 113116). Eelnevaga rõhutatakse indiviidi lahutamatust keskkonnast (lk 118). Indiviidist väljas on see, mis ei ole kesknärvisüsteemis (lk 122).

Meel on bioloogiline süsteem, mis muudab ajuvälise keskkonna muutused närviimpulssideks (lk 123). Närviimpulssidest viib keeruline rada asjade tajumiseni. Seevastu teadvus (Minu Ise) on psüühiline protsess, mille tulemusena kogetakse organismi enese psüühikat (lk 140), mis ei ole kaasasündinud ega peegelneuronite süsteemi korrelaat, vaid individuaalsel kogemusel põhinev organismi omadus, mis kujuneb eluajal (lk 141-143). Teadvus on keelelise ehk sotsiaalse ja meelepõhise infotöötluse ühtsuse olemuslik tunnus, mis moodustub keelemärgi tekkimisel (lk 348). Teadvus on Minu Ise kogemus, mille kogemise meeleorganeid ei ole meile teadaolevalt olemas (II kd, lk 293). Korduvalt tsiteerib Toomela Võgotskit (1934), kelle järgi „peegeldab teadvus end sõnas nagu päike väikeses veetilgas“, „sõna suhestub teadvusega nagu väike maailm suurega“, „mõtestatud sõna on inimliku teadvuse mikrokosmos“ (lk 349). Teadvusele ei ole kättesaadavad mitte psüühikas toimuvad protsessid, vaid ainult nende protsesside tulemused (lk 351).

Kõne on psüühiline protsess, mis vahendab neid välise ja sisemaailma asju-seoseid, mille aistimiseks meil retseptorid puuduvad (lk 145). Meeleülene maailm avaneb meile tänu keele kasutamisele mõtlemises, kõnelise ja meelelise infotöötluse sünteesis (lk 166, 180). Neli kõne funktsiooni on suhtlemine, informatsiooni saamine, kogemuse mittebioloogiline säilitamine tulevastele põlvedele ja kogu psüühika ülesehituse muutmine (lk 168-172).

Märk on „terviklik ühik, mis sisaldab osadena meelelistest tunnustest koostatud kujundi ja sellega seostuva välise maailma aspekti või teise kujundi“ (lk 183-184; 300). Loodetavasti võiks autori sõnastust mõista nii: märk sisaldab kahte osakujundit, millest üks koostatakse meelelistest tunnustest, teine meeleliste tunnustega seostuvast välise maailma aspektist või teisest kujundist. Toomela jagab märgid omavahel seotud meelepõhisteks ja keelelisteks märkideks (lk 189-190). Märgi tekkeks on vaja kogu psüühilist funktsionaalset süsteemi, enamgi, psüühika peab märgi tekkeks suhestuma keskkonnaga. Märgi säilitamiseks on vaja osa psüühikast, mälujäljena säilivat meeleliste tunnuste erilist mustrit, mis vastab mõtlemise käigus eristatud kindlale keskkonnaaspektile. Sõna, keelemärk peegeldab inimese teadvust, inimest kui tervikut, 
tehes seda mingis kindlas, erilises aspektis. Sõna mõte on kogum kõigist võimalikest sõna meelelise vormi seostest teiste psüühiliste märkidega; sõna tähendus on üks mõtte tsoone, see on elavas kõnes (kas seesmises ehk psüühilises või välises ehk sotsiaalses kõnes) realiseerunud sõna mõtteliste seoste kogum (II kd, lk 36).

Põhjuslikkust tuleb otsida struktuurist. Struktuur ehk süsteem on uudsete omadustega tervik, mis moodustub kindlates suhetes eristatavatest elementidest (lk 203). Inimkäitumist kirjeldab Toomela omailmaga täiendatud Anohhini funktsionaalne süsteem (lk 208-220). Psüühika tekkeks lisatakse funktsionaalsesse süsteemi meeldejätmine, mõtlemine ja tegevuse planeerimine, osal psüühilistest organismidest ka emotsioonid (lk 222). Psüühika kätkeb individuaalse kogemuse salvestamist ja mõtlemist. Mõtlemisega eristatakse olulisi aistinguid ja pidurdatakse ebaolulisi (lk 225) - see on individuaalse kogemuse seesmine organiseerimine (lk 227). Emotsioon on kogu organismi tegevust integreeriv sündmus või süsteem, mis on selle sündmuse vallandumiseks vältimatult vajalik; eriline komponent keerulises psüühilises funktsionaalses süsteemis. Tunne on emotsioonis vallanduvate biootiliste ja psüühiliste protsesside kogemine (lk 236). Psüühikas kui tervikus peavad osalema motivatsioon koos vajadustega, mälu, meeled ja meelte vahendusel kogetu organiseerimine ehk mõtlemine ning otsustamine ja planeerimine. Lisanduda võivad ka emotsioonid, kuigi lihtsama psüühika korral ei pruugi see juhtuda. Psüühika kui terviku omadused peavad erinema selle osade omadustest. Uudsete omadustega Minu Ise terviku tekkimisel peavad selle osade omadused muutuma (lk 274).

Indiviid on organism, kellel on isiksus. Isiksus on indiviidi potentsiaalsete psüühiliste funktsionaalsete süsteemide organisatsioon (parem oleks organiseeritus - JK), mis muutub organismi ajaloos ja situatsioonides ning mis määrab indiviidi unikaalse kohanemise oma keskkonnaga (lk 293). Isiksuse kirjeldus sisaldab vältimatult kirjeldust organismi piirangutest, funktsionaalsete süsteemide vormidest, mida organism sellel arenguastmel pole põhimõtteliselt võimeline koostama (lk 294). Kõige tänapäevasem ja populaarsem isiksuseteooria („suur viisik“ - JK) osutub kakssada aastat ajast maha jäänuks (lk 292).

Keelemärgi kasutamine on alati teadvustamine: keelemärk osutab korraga nii otseselt välises maailmas asuvale füüsikalisele sündmusele kui ka psüühika sees mõnele teisele meelepõhisele või keelelisele märgile. Keelemärgi kasutamisel me kogeme psüühikat, teisi psüühilisi märke (lk 346-347). Keelemärke on võimalik kombineerida eri viisidel ja kasutada kontekstides, mis pole meelepõhiste märkide korral võimalik (lk 348).

Areng on struktuuri hierarhiline reorganiseerimine - protsess, mille käigus struktuuri koosseis muutub koos tema kui terviku omaduste muutumisega. 
Arenguna saame mõista nii teistsuguste omadustega uudset tervikut, mis tekib uue elemendi lisandumisel olemasolevasse tervikusse, kui ka olemasoleva terviku lagunemisel tekkivaid - olemasolevaga võrreldes samuti teistsuguste omadustega - uusi, vähem keerukaid tervikuid, mis olid enne suurema terviku osad. Areng on hierarhiliselt keerulisem terviklik süntees, mille vastandprotsess ehk lagunemine on taandareng ( $1 \mathrm{k} 356)$.

Teadvus, mis seisneb enese meelemärgilise psüühika kogemises, areneb teadvusteadvuseks, enese psüühika kogemuse kogemiseks. Nii keelemärgi kui ka teadvuse arengus on kvalitatiivsed astmed, igaüks eelmisest keerulisem (lk 362). Iga organismi tegevus on sihipärane, suunatud mingi eesmärgi saavutamisele. Üks sihipärase käitumise vorme on tahteline käitumine (lk 366). Vabadus aga on võime end ületada (lk 369-370).

Teadvustamine ja tahe on võimalikud vaid nende psüühiliste nähtuste korral, mille oleme keelemärgiga sidunud (lk 391). Tahe on teadvuse avaldus ja seda võib mõista kui eneseületamist (lk 390-391). Tahtevabaduse suunas arenetakse mööda ühtteistkümmet enese kogemuse teadvustamise teed (lk 391). Keelemärgilise kogemuse alusel eristatakse mõtlemises viit arenguliselt üksteisele järgnevat mehhanismi. Igaüks võimaldab keelemärkides väljendada ja mõtestada kvalitatiivselt uut liiki informatsiooni. Selle põhjal on võimalik eristada viit teadvustamise vormi, iga järgmine komplekssem kui arenguliselt varasemad. Erineda võivad seejuures nii teadvustamise mehhanism kui ka tegelik teadvustatud kogemus (lk 402-403).

Kõnega vahendatud mõtlemise abil kavandatakse oma tegevust. Muu hulgas mõtestame ümbritsevat keskkonda situatsiooniaferendi (sic!) alusel. Tagasiaferentatsioon aga võimaldab teada saada, kas oleme plaanitud eesmärgi saavutanud (lk 462). Kultuur on tehiskeskkond, mis vastab organismi keelemärgiliselt vahendatud psüühikale (lk 547).

Teises köites täpsustab Toomela Minu Ise teooriat, avades arengustaadiumide sisu (allpool viited lehekülgedele II köite järgi, kui pole märgitud teisiti). Sadade inglise keeles avaldatud uurimistulemuste tõlgendamine meenutab kadunud Peeter Tulviste esimest nn välisuuringuid analüüsivat väitekirja, niisama kui tänapäevaseid metauuringuid. Kokkuvõtlikult esitatakse Minu Ise teooria järgsete arengustaadiumide põhitunnused tabelis lk-del 86-90. Hiljem (lk 147) möönab autor, et ehkki vaimse arengu staadium on sellise märgilise mõtlemise vormi arengu võimalus, mis iseloomustab psüühikat tervikuna, jääb arengustaadium ise printsiibiks, olemata konkreetne ettemääratud tunnus. Seega - ja liiati - pole staadiumide arv piiratud.

Kokkuvõtvas tabelis esitatud staadiumid on bioloogiline alus, assotsiatiivsed märgid (sünnist), asjamärgid (5.-6. elukuust), situatsioonimärgid (9.10. elukuust), sünkreetsed mõisted (1aastaselt), asjamõisted (1,5aastaselt), 
igapäevamõisted (3aastaselt), loogilised mõisted (7aastaselt) ja süsteemsed mõisted (12aastaselt). Tabelis lk-1 171 lisandub (tõsi, küsimärgiga) nimetatud üheksale kümnes staadium - süsteemmõisteline tegevuse planeerimine (18aastaselt). Need staadiumid seostuvad aju küpsemisega. Kirjeldatud on staadiumipõhise kogemuse sisu, tegevuse ülesehitust ja ettevalmistust järgmiseks staadiumiks. Ükski arengustaadium ei asenda eelmist psüühikas tervikuna, kuid iga mõiste peab läbima sama arengutee, samad staadiumid (lk 116).

Mõistus jääb heterogeenseks, sisaldades kõrvuti eri arengustaadiumide märke (seals). Organismi jõudmine uude staadiumi võimaldab märgiliselt kogeda väliskeskkonnas teatud tüüpi uusi seoseid. Nende märkide alusel luuakse uued tegevused, mis omakorda loovad tehiskeskkonna, mille ülesehitus on aluseks märkide järgmise arenguastme kujunemisele. Teisisõnu ei pea organism kohanema mingisuguse tulevikus võimaliku keskkonnaga, kuivõrd loob sinna jõudes ise keskkonna. Sellist tehiskeskkonda traditsiooni ja sotsiaalse päritavuse kaudu põlvkonniti alles hoides on organismidel konkreetne keskkond, mille ülesehituse varieeruvusega on kasulik kohaneda (lk 187). Iga järgmise arengustaadiumi valmistavad ette tegevuse planeerimine eelmises arengustaadiumis kujunenud märkide alusel ja selle tegevuse eesmärkide kogemine. Areng eeldab vältimatult aktiivset tegevust (lk 202).

Kõrvu bioloogilisega paistavad ka psüühilises õppimises olevat teatud ajaaknad või kriitilised perioodid, mis kestavad aastaid. Näiteks ei kesta elu lõpuni võime omandada emakeelt. Kui inimlaps eriliste asjaolude tõttu esimesel kümnel eluaastal inimkeele keskkonnaga kokku ei puutu, jäävad nii keeleoskus kui ka üldine vaimne areng väga tagasihoidlikule tasemele isegi siis, kui arengukeskkond on toetav. Samas saab vähemalt esimese 6-7 eluaasta äärmiselt piiratud arengukeskkonnast tingitud psüühilise arengu puudujäke soodsas arengukeskkonnas suurel määral kompenseerida (lk 224).

Psüühika kaasasündinud alus ei ole keerukas ja abstraktne arusaam füüsikalise maailma asjade omavahelise suhte olemusest, vaid meeletunnuste sidumisel õpitud arusaam nägemis- või muu meelega kogetavast. Erandiks võib siin olla vastsündinutel avastatud koguste üldise hindamise võime (lk 238, sel alateemal ptk-d 8 ja 9). Välistatud on kaasasündinud nn amodaalne ehk mittemeeleline abstraktne teadmine. Isegi kõige abstraktsemad ülemeelelised teadmised toetuvad keelemärkidele, millel on alati meeleline märgi vorm (lk 264).

Psüühika arengustaadiumide eristamisel on analüüsiühik märk. Minu Ise peegeldub märgis nagu päike veetilgas. Märk suhestub psüühikaga nagu väike maailm suurega, nagu elus rakk organismiga, nagu aatom kosmosega (lk 282-283). Kogemuse muutumise aluseks on uudne tegevus, mis omakorda muutub uudse kogemuse kujunemisel. Sellisel uudse kogemuse - uudse tegevuse - tsüklil põhinebki psüühika areng. Meie Minu Ise sünnib tegevuses, mis 
muutub kogemusega (lk 77). Me eristame ehk diferentseerime tervikut, sünteesides selle muust maailmast. Tegevus on (põhimõtteliselt) sünteesimine. Tegevuse roll vaimses arengus on elementide sünteesimine uudseteks tervikuteks (lk 79-80). Eristatakse (sihipärast) tegevusfunktsiooni, nt haamer, ja (sihipäratut) kogemusfunktsiooni, nt kastev vihm (lk 105).

Asja keelelised omadused „käivad koos“ asja liikumisel ja liigutamisel tema keskkonna suhtes (lk 285). Asjamärgid kujunevad alates 5.-6. elukuust ning see on seotud (vaatamis-)tegevusega ja sellele vastava nähtavat maailma uuriva käitumisega. Asjamärgid kujunevad psüühiliselt, s.t õppimise käigus. Asjad ei ole Minu Ise maailmas kaasasündinud nähtused (lk 293). Asjamärkide psüühilisel sidumisel situatsiooniga muutuvad asjamärgid keerulisema terviku osaks (lk 317).

9-10kuused lapsed õpivad situatsioonimärkide kujunemise kaudu tundma asjade seaduspärast muutumist kokkupuutes teiste asjadega. Mõnikord on muutused seotud lapse enda eesmärkide ja tegevustega, teistel juhtudel aga asjade omavahelistes suhetes tekkivate muutustega, millesse laps oma tegevusega otse ei sekku. Esimesel juhul seob asjamärke situatsioonimärkideks tegevusfunktsioonimärk, teisel juhul kogemusfunktsioonimärk (lk 308). Kõne areng algab pärilikul alusel kujunenud funktsionaalsete süsteemide naturaalsest arengust, mis toetub sotsiaalsele suhestumisele keskkonnaga ja viisile, kuidas selles suhtes olevad inimesed tõlgendavad lapse tegevust aktiivselt. Lapse ja tema sotsiaalse keskkonna aktiivses suhtes kujuneb lapsel kõne-eelne indeksmärgiline väljendus, mis esimese eluaasta lõpuks võib väliselt kõnet meenutada. Tegemist on kõne naturaalse arengu aspektidega, mida leidub ka loomadel. Kõne kujuneb uudse emergentse (eesti keele seletava sõnaraamatu järgi areneva, esilekerkiva, emergeeriva) nähtusena mittekõneliste meelemärgiliste protsesside sünteesimisel sotsiaalse keskkonnaga suhestudes. Staadiumi lõpuks on laps valmis kõnet omandama (lk 379).

Kõne ehk keelemärkide kasutamise areng algab sünkreetsete mõistete ehk esimeste sõnadega. Sünkreetseid mõisteid kasutatakse ükshaaval, mistõttu ei jaotata psüühilises kõnetegevuse planeerimises keelemärke eri klassidesse. Sünkreetsed keelemärgid osutavad subjektiivsel alusel kujunenud mehhanismide kaudu ükskõik millisele eelnevas meelemärkide staadiumis moodustunud märgile (lk 380-381). Sünkreetsete mõistete staadiumis sõnu ei kombineerita ja piiratud infotöötlusvõimet avardavatesse känkudesse mahub sõnavorm koos ühe meelemärgiga (lk 398). Asjamõistes sünteesitakse sõnavorm, asjamärk ja keelemärk, sõnu saab hakata sünteesima kõrgema taseme tervikutesse. Piirdumine kahe keelemärgi kombineerimisega tähendab võimet eristada asja ja selle omadusi, kuid mitte veel situatsioone. Arenevad esimesed sõnade sotsiaalse kombineerimise ehk grammatikareeglid (lk 400). 
Asjamõistelistest asjasõnadest kujunevad edaspidi nimisõnad, tegevussõnadest tegusõnad, tunnustesõnadest omadussõnad, suhtesõnadest arv- ja määrsõnad (lk 407). Asjasõnade alus on kahemõõtmeline eest- või külgvaade, mis seostub prototüüpsete kategooriatega (lk 426). Tegevussõnad osutavad hästi ettekujutatavatele tegevustele, mis on seotud kindlate liigutusmustrite või asjadega. Nende kasutuskontekst laieneb vähehaaval, nende tähendusi piirab vähearenenud grammatika (lk 437). Asjaomased tunnustesõnad arenevad enne situatsioonilisi (lk 438).

Igapäevamõistete staadiumis seotakse väljendiks üle kolme sõna, eristuvad kõik sõnaliigid ja grammatikareeglid, mis võimaldavad asuda kõneliselt mõtestama kogu meeltega kättesaadavat maailma. Ülemeelelise maailma jaoks pole keelekasutus veel piisav (lk 447). Täht kui kõneldava keele hääliku kohta käiv keelemärk saab areneda igapäevamõistena, kuna sel juhul diferentseeritakse kuuldav, nähtav või artikuleeritud kõne üksteisega suhestunud elementideks, kas hälikuteks või tähtedeks, ja need elemendid suhestatakse kas omavahel või siis mõne sõnaga, mis märgib ühte „nime“ (lk 466).

Loogiliste mõistete staadiumis sünteesitakse meelekogemust kirjeldav keelemõiste temale endale osutava teise keelemõistega. Kujuneb uus mõtlemise vorm, kus samas mõtte struktuuris võib eristada üksteist täiendavat mõtet välisest maailmast ja mõtet sellest, kuidas me välise maailma üle mõtleme. Avaneb tee meeleülesesse maailma (lk 477), areneb kõneline kõne üle mõtlemine ehk metalingvistika (lk 478). Metalingvistika arengut toetavad võõrkeele- ja kirjaoskus (lk 481-482). Metalingvistika on ühtlasi teadvuseteadvuse ehk metakognitsiooni olemus (lk 487).

Tõeline ehk süsteemne mõiste on element iseenda Minu Ise struktuuris, ühtlasi on see põhjendatud vastavuses välise maailmaga. Tõelistes mõistetes mõtlemise olemus on mõista teadvusteadvustatud maailma ja iseenda ühtsust (lk 524).

Kolm ääremärkust teise köite teooriakonspekti juurde. Esiteks võinuks (seda Toomela tervikteooriat kõrgelt hindava Karl Karlepi meelest) staadiumide kirjelduses veidi enam kajastada hoiakuid, emotsioone ning sisekõne osa tegevuse planeerimises, laiemalt - psühholingvistikat. Teiseks jagub raamatusse millegipärast minimaalselt näiteid Eesti laste kõne kohta. Kolmandaks väärinuks kas avaramat või, vastupidi, eesti keele spetsiifilist käsitlust inglise keelel põhinev näide tähenimede omandamise kasulikkuse kohta (lk 468).

Sünnipära ja keskkonna kestva vastastikmõju idee tundub esimese hooga triviaalsusena. Näiteks kirjutab Rein Raud (2017), arvustades Alain Badiou „Eetikat“, et „... iga inimolend on kujunenud suhetes oma keskkonnaga, korraga seda muutes ja mõjusid vastu võttes" (lk 30-31). Selline hinnang jääks ebaõiglaselt pealiskaudseks. Lähenedes inimese psüühikale tervikuna, pakub 
Toomela ühtlasi oma lahenduse või tõlgenduse mitmele olulisele probleemile, jõudes välja elu mõtte ja tahtevabaduseni. Toomela teoorias eristub teistest olenditest inimene kui ainus teadvusega olend, kes mitte ainult ei korralda oma toimimist individuaalse kogemuse põhjal, vaid suudab mõelda iseendast, kasutades selleks keelemärgilist kõnet.

Paljude kõrvalteemade seas kajastuvad teoses Toomela inglise keeles viimasel kümnendil avaldatud seisukohad psühholoogiateaduse rappaminekust viimasel 60-80 aastal (Võgotski hinnangul algas asjaomane allakäik Põhja-Ameerikas 1920. aastate keskel). Toomela visandab seisukoha rekapitulatsiooniteooria kognitiivse variandi kohta järgmiselt: igale vaimse arengu astmele peab olema eelnenud kindel vaimse arengu aste, niisama kui evolutsioonis astub mõistus uuele märkide astmele. Uudset tehiskeskkonda luues jõuab aju mõistusele järele (II kd, lk 188). Kõrvuti osutustega psühholoogia peavoolu, laiemalt põhjuse ja tagajärje skeemi saamatusele, mis on kestnud kümnendeid, täpsustab Toomela, kes autoritest järgib Lev Võgotski õpetust õigesti (mis ei välista loovust) ja kes on hälbinud lihtsustavale rajale. Toomela esitab teesid ka vaesuse ja kliimaprobleemide käsitlemiseks tõelistes (süsteemsetes) mõistetes.

Teose tutvustamist ja arvustamist siinse ajakirja veergudel õigustab Aaro Toomela osutus, et tema teooriast saaks sündida täiesti uus pedagoogika (II kd, lk 557). Otsides teose probleemikäsitlustest sobivaid viiteid, leidsin esimeseks alusteadmise õppe viljakusest. Kui sünnipärased eeldused oleksid määravad, jääks koolile karjase roll. Keskkonna kõikvõimsus võimaldaks kujundada uut inimest tema sünnipärast sõltumata. Kahe äärmuse vahepeale jääb Carol Dwecki (2014) propageeritav usk pingutuse viljakusse. Toomela teadvusteooria kinnitab seevastu selgelt ja jõuliselt, et meie saatuse taga on edasi- ja tagasisidestatud keskkonnamõju. Järelikult pole põhjust maha matta ei koolieelset, kooliea- ega eripedagoogikat, ammugi siis andragoogikat. Toomela teooria ei välista sünnipäraste eelduste (olulisi) erinevusi, mõistagi ka mitte ebasoodsa keskkonna mahakiskuvat mõju. Muu hulgas viitab Toomela ühele Argentina uuringule, milles võrreldi 6-14 kuu vanuste laste A-mitte-B ülesande lahendamise seost nende kasvukeskkonnaga. Ebasoodsatest oludest lapsed kaldusid valest kohast otsima sagedamini kui jõukate vanemate võsud (II kd, lk 334).

Järgmisena võiks selgitada, missugune õpe kannab vilja, missugune jääb viljatuks või neutraalseks. Parafraseerides Toomelat, tuleb teadmist või oskust kujundades küsida mitte ainult seda, kas tuldi toime, vaid ka seda, kuidas seda tehti (II kd, lk 145). Eks matemaatikaõpetaja nõua lahenduskäiku. Samas on tõsiasi, et õpilaste vigade ja mõttekäikude iseloomu vastu võiks laialdasemalt huvi tunda. 
Edasi, jõukohasus eeldab toetumist lapse/õppuri arengustaadiumi piirangutele ja võimalustele. Toomela staadiume saab hõlpsalt suhestada nii juhtiva tegevuse raamistikuga kui ka logopeedias kasutusel oleva viisiga kirjeldada (mitte-)eakohast kõnet. Triviaalsust trotsides osutatagu siinkohal ka süveneva individualiseerimise potentsiaalile. Praktika seab individualiseerimisele piire, mida osaliselt avardab tehnoloogia.

Toomela esitab küllalt põhjaliku seisukoha tähenduseta häälikuühendite kasulikkusest häliku ja tähe vastavuse õppes ning selle põhimõtte võimalikust laiendamisest uudsete matemaatika-, füüsika- ja keemiateadmiste vallas. Küündimata küll autori mõtte avarama lahtimõtestamiseni, viitan meelsasti tähenduseta „sõnade“ kui metoodilise võtte laialdasele rakendamisele nende Eesti laste hääldama õpetamisel, kellel see iseenesest ei laabu. Kas see idee aga vastandub üle saja aasta vanusele koduloolisusprintsiibile, on raske hinnata. Veel laiemalt võib seda vaagida seoses õppekava kontsentrilisusega. Nimelt kaasnevad selle idee rakendamisega alama astme õppes ülelihtsustamine ja teabemoonutused, mis tunduvad ühelt poolt paratamatusena, teisalt arusaamatu ajaraisuna (vt II kd, lk 337).

Õige laias võtmes sobib siinkohal osutada, et mõttetu oleks välistada viljaka teooriapõhise pedagoogika võimalikkus. Samas on senised mõjusad sekkumisviisid kas jõudnud teooriani, üldistades edukat õpetamispraktikat (nt Siegfried Engelmann) või sobitades-kohandades teooriat igapäevase õppe ja vaatlusega (Wilhelm Steiner, Karl Karlep ja Eha Vihm). Pole puudus arvajatest, kes väidavad end teadvat, kuidas ei peaks õpetama. Intrigeerivam on leida oma erialal suurepäraseid loojaid, kes kinnitavad, et nad kujutavad ette, kuidas peaks seda tegema. Kuivõrd esimeses köites lubatud tulevikuteemade hulgas kajastub pedagoogika vaid kaude, jääb läbimurret oodates meil üle loota kas autori meelemuutusele või tema jüngritele.

Vormistusest. Esimese köite 590 lehekülge jagunevad nelja ossa, 20 peatükist tervelt kaheksa ehk peaaegu $200 \mathrm{lk}$ toestavad väljapakutud teadvuse struktuuri näidete-argumentidega (autori jaoks) autoriteetidelt ja empiirilistest andmetest. Teise köite 654 lehekülge jagunevad 17 peatükki, need omakorda kahte ossa; teooriale kulub umbes 200 lehekülge, näidetele-argumentidele pisut üle 300. Teos(t)es on kokku 120 leheküljel viidatud kolme viimase aastatuhande autoritele. Olulised, kuid teemaga vähem seotud kommentaarid on mahutatud joonealustesse viidetesse, mis on paigutatud kuni kolmele leheküljele.

Kujunduslikult on hästi õnnestunud pikkade tsitaatlõikude eristamine taandega, vähem abistab lugejat väikeste erinevustega kaldkirja kasutamine alapealkirjade liigendamisel, seda esimeses köites (nt lk 107 ja 113, kujundaja Merle Moorlat). Kursiivi kasutatakse ka määratluste eristamiseks, paksus kirjas kursiiv ilmub esimest korda esimese köite lk-l 346. Pealkirjade ja teksti 
liigendus teises köites soodustab jälgimist igati (küljendus Anna Lauk). Mõlemad raamatud (autori sõnul ühe raamatu kaks esimest köidet) on soliidses $130 \times 210$ kõvaköitelises formaadis (kujundaja Soraya Jesus Salomão).

Eesti keele väljendusjõudu tugevdavad sõnavara-lisandused: subiteerimine (väikeste hulkade eksimatu arvuline pilkhinnang, ingl subitizing), teadlemine (ingl sciencing) ja kängud (ingl chunks), kaheldavaks jääb emergentse vajalikkus. Kiiduväärse järjekindlusega eristatakse keelt kõnest. Tõsi, eelnevaga kõrvu eirab autor oskussõnu, kirjutades vaimse arengu häirest, samuti kui häälikuanalüüsist häälikanalüüsi tähenduses (II kd, lk 486). Igati akadeemilised on pikkade tsitaatide tõlked esimeses köites. Vastavalt esimest ja teist köidet toimetanud Tiina Sammelselg ja Katrin Kern on koos II köite korrektori Merle Hirvlaanega õigekirja eest viljakalt hoolitsenud. Märkasin vaid väheseid näpuvigu. Teose autorit lähendavad lugejale autori eraelulised detailid Sepamäest, rohelisest teest ja Sorayast.

Mõnigi autori ebatraditsiooniliselt sõnastatud mõttekäik on jälgitav kohase vaimupingutusega; tekst sobib pigem doktoriõppesse kui bakalaureusetasemele. Lugemisvaeva saanuks siin-seal leevendada sõnajärje ja liigendusega ning elliptilisi fraase vältides. Kohati on kaheldav valitud stiiliregister. Iseäranis teises köites leiab kõnekeelsust rohkem. Isikupära ja huumorit jagub selletagi piisavalt. Tulevastes köidetes võiksid imikud pigem silmitseda ja kõnehäälikuid lausuda, kui piirduda siinkohal mõne näitega. Viited varasemate aastatuhandete autoritele sobiks anda käsikäes esmaavaldamise aastaga, kui kasutatud tõlge ja (või) uusväljaanne dateeritakse oluliselt hilisemana.

Üllitis on pälvinud meedia tähelepanu, vestlust autoriga saab järele kuulata Vikerraadio saates „Labor“ (2017). Teine, ERRi kultuuriportaalis järele vaadatav salvestus pärineb Tallinna ülikooli õpetlaste tänuväärt ponnistusest süüvida üksteise teostesse TÜHI pop-up-seminaril (2017).

Kokkuvõtteks. Esimesed 1264 lehekülge uut eesti mõttelugu on ilmunud. Aastal 2016 lubas autor järge, ikka köide aastas. Kolme köidet kokkulangevast astmete järjestusest inimlapse psüühika arengus ja eluslooduse evolutsioonis. Kahte rikkalikult illustreeritud köidet visuaalse kunsti arengust. Vähemalt ühekaupa raamatuid (a) psüühika elementidest ja nendevahelistest seostest, (b) põhjuslikkusest, (c) Brasiilia kirjaoskamatutest, (d) sotsiaalse maailma teooriast. Teise köite lõpus viitab autor, et olud sunnivad piirduma esialgu ühe lisaköitega, teemaks individuaalse ja liigi arengu sarnasused rõhuasetusega joonistamise ja maalimise arengul. Toomela väljendab valmisolekut jagada inimkonna suurimate mõtlejate saatust, keda pole kunagi kohe mõistetud (II kd, lk 474), ehkki inimkond on autori hinnangul tasapisi jõudmas maailma struktuur-süsteemse olemuse mõistmise lävele (II kd, lk 538). Lugejal avaneb võimalus pürgida progressi esirinda. 


\section{Kasutatud kirjandus}

Dweck, C. (2014). Developing a growth mindset. Retrieved from

https://stanfordconnects.stanford.edu/watch/developing-growth-mindset/.

Karlep, K. (1998). Psühholingvistika ja emakeeleõpetus. Tartu: Tartu Ülikooli Kirjastus.

Raud, R. (2017). Kõneleb kuningas Nälg. - Sirp, 50, lk 30-31.

Võgotski, L. (2004). Mõtlemine ja kõne: psühholoogilised uurimused. Tartu: Ilmamaa. 